\title{
PRÁTICAS DE ENSINO DA LEITURA: A FORMAÇÃO DE LEITORES COMPETENTES E O PAPEL DO PROFESSOR
}

\author{
PRACTICES OF TEACHING READING: THE FORMATION OF READERS AND \\ COMPETENT TEACHER'S ROLE
}

\author{
Juçara Moreira Teixeira \\ Universidade Federal de Minas Gerais
}

RESUMO: Nesse artigo, apresentar-se-á uma pesquisa desenvolvida no Ensino Fundamental, cujos objetivos foram: realizar um trabalho de leitura em sala de aula, para assim analisar o processo de aprendizagem dos alunos e o efeito da intervenção no desenvolvimento de suas habilidades de leitura; e (re)pensar o papel do professor no processo de ensino-aprendizagem da leitura. Foram adotadas as concepções de letramento (SOARES, 2010; ROJO, 2010; KLEIMAN, 2010), a teoria sociocognitiviva e interacional da linguagem (KOCH, 2011), a concepção de "dialogismo" (BAKHTIN, 2011) e as discussões sobre intertextualidade (KOCH, BENTES e CAVALCANTI, 2008; SANT'ANNA, 1998). Os resultados da pesquisa indicaram a relevância de se desenvolver atividades de leitura com objetivos definidos e que permitam ao aluno ampliar sua visão de mundo, tornando-o capaz de relacionar as aprendizagens entre si e à vida cotidiana. Da perspectiva do trabalho docente, ressalta-se a importância de o professor ocupar posições distintas no processo de ensino-aprendizagem, propiciando igualmente papéis distintos aos alunos ao lidarem com o saber representado na/pela leitura. Confirmou-se a necessidade de o professor ser um sujeito reflexivo, que encontra nas dificuldades de aprendizagem dos alunos fontes outras de intervenções e pesquisas, sempre (re)pensando seu papel no contexto de ensino-aprendizagem.

PALAVRAS-CHAVE: ensino; leitura; habilidades; aluno; professor.

ABSTRACT: In this paper, we will be presented a research developed in elementary school, whose objectives were: to conduct a reading work in class, so as to analyze the learning process of the students and the effect of the intervention on developing their reading skills; and (re) think the role of the teacher in the teaching-learning of reading. We adopted the conceptions of literacy (SOARES, 2010; ROJO, 2010; KLEIMAN, 2010), the theory social-cognitive and interactional language $(\mathrm{KOCH}, 2011)$, the concept of "dialogism" (Bakhtin, 2011) and discussions about intertextuality (KOCH, BENTES and CAVALCANTI, 2008; SANT'ANNA, 1998). The research's results indicated the importance of developing reading activities with clear objectives and that allows students to expand their world view, making they able to relate learnings to each other and learning to everyday life. From the perspective of teaching, we emphasize the importance of the teacher occupies distinct positions in the teaching-learning process, providing equal distinct roles to students in dealing with knowledge represented in / by reading. We confirmed the need of the teacher to be reflective person, who finds the learning difficulties of students which are sources to other interventions and research, always (re) thinking about hisher role in the context of teaching-learning.

KEYWORDS: teaching; reading; skills; student; teacher. 


\section{Revista do SELL}

v. $4, n^{\circ} .1$

ISSN: $1983-3873$

\section{Considerações iniciais}

As avaliações sistêmicas realizadas nos últimos anos (Prova Brasil, PISA, ENEM) têm demonstrado a necessidade e a urgência de se investir no trabalho com a leitura em sala de aula. Em 2009, o PISA ${ }^{1}$, cujo foco foi a leitura, avaliou 20 mil brasileiros estudantes da fase final do Ensino Fundamental. O Brasil atingiu a média de 412 pontos em leitura, equivalente ao nível 2 (dois) ${ }^{2}$, considerado pelo exame como básico ou moderado.

Do mesmo modo, os resultados da Prova Brasil de 2009 indicam que a proficiência dos estudantes nos anos iniciais do Ensino Fundamental em Língua Portuguesa foi de 184,3 pontos e 244 nos anos finais, equivalente aos segundo e terceiros níveis, respectivamente, da escala de 5 (cinco) níveis de proficiência em leitura.

Diante disso, percebe-se a necessidade premente do investimento no ensino da leitura nas escolas, como já apontam os Parâmetros Curriculares Nacionais e os estudos da área (ROJO, 2010; SOARES, 2010; MATENCIO, 1994; ANTUNES, 2010).

Foi nesse contexto que surgiu o estudo ora apresentado, cujo objetivo era, por meio de uma pesquisa-ação de cunho qualitativo, desenvolver um trabalho de leitura em sala de aula, para assim analisar o processo de aprendizagem dos alunos e o efeito da intervenção no desenvolvimento de suas habilidades de leitura, em especial as referentes às "Capacidades de apreciação e réplica do leitor em relação ao texto"3. Buscou-se também (re) pensar o papel do professor nesse processo de ensino-aprendizagem e a sua relevância nesse contexto.

\footnotetext{
1 "O Pisa, sigla do Programme for International Student Assessment, que em português,(sic) foi traduzido como Programa Internacional de Avaliação de Alunos é um programa internacional de avaliação comparada, aplicado a estudantes da $7^{\text {a }}$ série em diante, na faixa dos 15 anos, idade em que se pressupõe o término da escolaridade básica obrigatória na maioria dos países. Esse programa é desenvolvido e coordenado internacionalmente pela Organização para Cooperação e Desenvolvimento Econômico (OCDE), havendo em cada país participante uma coordenação nacional. No Brasil, o Pisa é coordenado pelo Instituto Nacional de Estudos e Pesquisas Educacionais Anísio Teixeira (Inep). As avaliações do Pisa acontecem a cada três anos e abrangem três áreas do conhecimento: Leitura, Matemática e Ciências, havendo, a cada edição do programa, maior ênfase em cada uma dessas áreas.” (IFF, p. 1, 2013)

2 "No Nível 2, os estudantes são capazes de responder itens básicos de leitura, tais como situar informações diretas, realizar inferências fáceis de vários tipos, determinar o que significa uma parte bem definida de um texto e empregar certo nível de conhecimentos externos para compreendê-lo.” (IFF, p.5, 2013).
}

3 ROJO, ROXANE. Letramento e capacidade de leitura para a cidadania. Disponível em: <http://web.me.com/rrojo/Roxane_Rojo/Espa\%C3\%A7o_Blog/Entr\%C3\%A9es/2009/2/24_Letramento_e_ capacidades_de_leitura_para_a_cidadania_files/Rojo_2004_CapacidLeitura_1.pdf >. Acesso em 26 out. 2010. 


\section{Revista do SELL}

v. $4, n^{\circ} .1$

ISSN: $1983-3873$

\section{O ensino da leitura e o letramento dos alunos}

Desde a década de 80, a leitura e a escrita têm ocupado lugar privilegiado nas discussões sobre o ensino de Língua Portuguesa no Brasil, sendo consideradas os pilares da aprendizagem e o lugar de onde se deve partir para se combater o fracasso escolar.

Como parte desse processo de discussão, foram elaborados os Parâmetros Curriculares Nacionais de Língua Portuguesa no ano de 1997, documento oficial que objetiva orientar o professor para a realização de um trabalho que garanta a aprendizagem eficiente da leitura e da escrita de modo abrangente, para assim se combater o fracasso escolar e, consequentemente, promover a melhoria da educação no país.

Segundo este documento, o ensino de Língua Portuguesa deve-se basear em concepções que, transformadas em práticas de ensino, propiciem o desenvolvimento da competência discursiva dos alunos. Essas práticas são assim definidas:

... práticas de ensino que têm como ponto tanto de partida quanto de chegada o uso da linguagem. Práticas que partem do uso possível aos alunos e pretendem provê-los de oportunidades de conquistarem o uso desejável e eficaz. Em que a razão de ser das propostas de leitura e escuta é a compreensão ativa e não a decodificação e o silêncio. Em que a razão de ser das propostas de uso da fala e da escrita é a expressão e a comunicação por meio de textos e não avaliação e correção do produto. Em que as situações didáticas têm como objetivo levar os alunos a pensarem sobre a linguagem para poderem compreendê-la e utilizá-la adequadamente. (BRASIL, 1997, p. 20-21).

Essa perspectiva de ensino estabelece para a escola o dever de formar cidadãos capazes de compreender e usar produtivamente as linguagens oral e escrita, em suas diversas formas e funções e nas diferentes situações de comunicação, proporcionandoIhes a oportunidade de participação em práticas reais de letramento ${ }^{4}$ e tornando-os sujeitos competentes discursivamente para atribuírem sentidos às construções simbólicas das sociedades.

Entretanto, não foi essa a perspectiva que durante décadas predominou nas escolas brasileiras. Segundo Antunes (2010), a ensino da língua materna, de modo geral,

\footnotetext{
${ }^{4}$ Segundo Kleiman (2005, p. 12), o termo "Prática de letramento" diz respeito a um "Conjunto de atividades envolvendo a língua escrita para alcançar um determinado objetivo numa determinada situação, associadas aos saberes, às tecnologias e às competências necessárias para a sua realização. Exemplos de práticas de letramento: assistir a aulas, enviar cartas, escrever diários".
} 


\section{Revista do SELL \\ v. $4, n^{\circ} .1$ \\ ISSN: $1983-3873$}

e da leitura, em particular, costumava pautar-se no estudo de frases descontextualizadas, no uso do texto como pretexto para estudo de questões gramaticais, deixando à deriva o estudo do texto como um "evento sociocomunicativo" e um construto social, histórico e linguístico-dicursivo - estes sim elementos que garantem uma análise global, acurada, reflexiva e crítica dos textos, ultrapassando assim questões pontuais de análise que pouco contribuem para o desenvolvimento de um leitor crítico.

Estudos sobre a leitura desenvolvidos no Brasil nas últimas décadas têm apontado caminhos outros para o ensino da leitura na escola. Perspectivas como a de letramento, segundo Soares (2010), Matencio (1994), Rojo (2010), Antunes (2010) e Kleiman (2010), defendem propostas de ensino que conduzam o aluno a uma atividade de leitura para além da decodificação do texto, ou seja, que o capacitem a compreender o texto e a extrapolá-lo, sendo capaz de dialogar com ele e de construir sentidos, bem como de agir socialmente por meio da linguagem.

Esses pressupostos teóricos defendem que os professores precisam comprometerse com o ensino da leitura, dedicando-se a formar alunos letrados. Segundo Rojo (2010), a formação de um aluno letrado, e de um cidadão consciente e capaz de circular em uma sociedade globalizada, implica em capacitá-lo a

(...) escapar da literalidade dos textos e interpretá-los, colocando-os em relação com outros textos e discursos, de maneira situada na realidade social; (...) discutir com os textos, replicando e avaliando posições e ideologias que constituem seus sentidos; (...) trazer o texto para a vida e colocá-lo em relação com ela. (p. 1-2)

Para Rojo (2010), capacitar o aluno a ler produtivamente requer abordagens adequadas dos textos e o desenvolvimento de habilidades de leitura, as quais englobam procedimentos e capacidades de natureza cognitiva, linguístico-discursiva e social que devem ser ativadas pelos aprendizes no processo de leitura e atribuição de sentidos aos textos.

Segundo a estudiosa, historicamente foram surgindo estudos sobre as habilidades envolvidas no ensino da leitura, as quais são agrupadas conforme o período em que surgiram e as semelhanças na perspectiva teórica no tratamento do ensino da leitura.

Desse modo, as habilidades de leitura estão divididas em três grupos de capacidades: "capacidades de decodificação", "capacidades de compreensão" e "capacidades de apreciação e réplica do leitor em relação ao texto", cada uma com 


\section{Revista do SELL \\ v. $4, n^{\circ} .1$ \\ ISSN: $1983-3873$}

características específicas. Apesar dessa subdivisão, ela ressalta que, no ensino da leitura, não é desejável que as habilidades sejam mobilizadas separadamente, mas sim concomitantemente.

Segundo a estudiosa, o que se viu e/ou ainda se vê em algumas práticas escolares é o desenvolvimento de, apenas, o primeiro grupo de habilidades, "Capacidade de decodificação". Em poucos casos, chega-se ao segundo grupo, o das "capacidades de compreensão"; e dificilmente abordam-se as "Capacidades de apreciação e réplica do leitor em relação ao texto".

Diante desse panorama, acredita-se que um trabalho consistente de ensino da leitura deve privilegiar os segundo e terceiro grupos de capacidades. Evidentemente, 0 primeiro grupo não pode ser relegado, uma vez que é pré-requisito para se alcançar os dois subsequentes.

Assim, diante da necessidade que se observa na realidade escolar brasileira e, em particular, das necessidades de aprendizagem dos alunos envolvidos na pesquisa, foi proposta essa pesquisa, a qual se ampara nas concepções de leitura mencionadas tanto para abordar os textos em sala de aula quanto para analisar os dados oriundos da intervenção pedagógica.

\section{Concepções teóricas e metodológicas para abordagem dos textos}

Nessa pesquisa, adotou-se a concepção sociocognitiviva e interacional da linguagem $(\mathrm{KOCH}, 2011)$ para tratar dos processos que envolvem a leitura de textos. Nessa perspectiva, o texto é considerado um "evento sociocomunicativo" (KOCH, 2011, p. 13), cuja existência se faz a partir da interação entre produtor e leitor, momento discursivo em que os sentidos são construídos.

Assim, deve-se considerar no processo de leitura o modo como o locutor e o interlocutor mobilizam seus conhecimentos para, assim, produzirem sentido nesse processo interacional de uso da linguagem. Segundo Koch (2011), ao ler um texto, o leitor mobiliza diversos conhecimentos armazenados em sua memória, os quais podem ser designados de conhecimento linguístico, conhecimento enciclopédico, conhecimento de textos e conhecimentos interacionais.

Nessa perspectiva, pode-se dizer que, ao ativar seus conhecimentos para fazer uma análise textual, o leitor deve considerar alguns elementos fundamentais para a compreensão global do texto, conforme aponta Antunes (2010): o domínio discursivo ao 


\section{Revista do SELL \\ v. $4, n^{\circ} .1$ \\ ISSN: $1983-3873$}

qual o texto pertence, o tema tratado, o propósito comunicativo, o gênero de texto, 0 locutor, o interlocutor, o contexto sócio-histórico, a relevância informativa do texto e a relação do texto com outros textos.

A intervenção pedagógica realizada com os sujeitos da pesquisa pautou-se, de modo geral, nessas concepções apresentadas e buscou desenvolver nos alunos as capacidades de leitura e modos de olhar para os textos que estão em consonância com os princípios teóricos apresentados até aqui.

O foco da pesquisa foi intervir e analisar os resultados obtidos durante e após a intervenção, para assim refletir sobre o processo de ensino-aprendizagem. Diante disso, fez-se um recorte teórico nas habilidades de leitura a serem pesquisadas, optando assim pela "capacidade de apreciação e réplica do leitor em relação ao texto (interpretação e interação)", com ênfase à "capacidade de percepção de relações de intertextualidade (nível temático)".

Como teoria e metodologia para abordar a "capacidade" selecionada na delimitação do objeto de estudo, adotou-se a concepção bakhtiniana de "dialogismo" (BAKHTIN, 2011) - a qual aborda a natureza dialógica dos enunciados - e as concepções de intertextualidade, conforme propostas por Koch, Bentes e Cavalcanti (2008) e Sant'Anna (1998).

Bakhtin (2011) afirma que os dizeres possuem uma historicidade, sem a qual eles não podem existir. Eles se constituem na interação dialógica com o outro, na "luta" com os pensamentos do outro. Assim, o enunciado é capaz de dialogar com o seu antecedente, assim como dialoga com aquele que lhe sucede, não existindo, portanto, dizeres inteiramente novos.

A partir desses estudos bakhtinianos sobre dialogismo, Julia Kristeva criou o termo intertextualidade, usado para significar as relações dialógicas estabelecidas entre textos. Assim, considerar-se-á, nesse trabalho, esse primeiro recorte teórico para tratar um dos tipos de dialogismo existentes.

Dentre as perspectivas existentes, considerou-se nessa investigação o que Koch (2008, p. 17) designou de "intertextualidade stricto sensu", para se referir ao processo em que um texto remete a outros "efetivamente produzidos", estabelecendo algum tipo de diálogo.

Nesse sentido, foram relevantes as categorizações de intertextualidade apresentadas por Sant'Anna (1998). Adotou-se a distinção que ele faz entre os tipos de intertextualidade, chamando-as de "intertextualidade das semelhanças" e 


\section{Revista do SELL}

v. $4, n^{\circ} .1$

ISSN: $1983-3873$

"intertextualidade das diferenças". A primeira caracteriza-se pela aproximação ao texto original, bem como a manutenção de sua orientação argumentativa ou narrativa. A segunda é marcada pelo distanciamento do texto original, marcada por inverter ou subverter o seu sentido.

Esse foi um recorte teórico necessário que orientou as escolhas pedagógicas no que tange às propostas de leitura dos textos, bem como direcionou a elaboração das categorias a serem adotadas para análise dos resultados obtidos.

\section{O ensino da leitura e as aprendizagens dos alunos}

A proposição do projeto surgiu dos diagnósticos realizados nas turmas, os quais revelavam a necessidade de desenvolver suas habilidades de leitura e escrita, processos complexos que requerem atividades com objetivos pré-definidos, bem delineadas, contínuas e motivadoras.

Foi elaborado um projeto de leitura e produção de textos, baseado no modelo de "sequência didática", conforme proposto de Dolz, Noverraz \& Schneuwly (2010).

Como a sequência didática aborda um gênero específico, optou-se por abordar o gênero "conto", pertencente ao "domínio do narrar" (DOLZ et al., 2010), pois os diagnósticos indicavam que os alunos ainda apresentavam dificuldades na escrita de textos narrativos. Além disso, segundo os $\mathrm{PCNs}^{6}$ (1997), deve-se desenvolver no aluno do 6ํano do Ensino Fundamental o domínio pleno dos gêneros narrativos.

Embora o foco do projeto de pesquisa estivesse voltado para a investigação da aprendizagem de determinadas capacidades de leitura, e da intertextualidade em particular, isso não impediu de abordar outros aspectos fundamentais no processo de leitura, no que se refere à compreensão textual e ao trabalho com o gênero, haja vista que o conhecimento das propriedades do gênero é de grande relevância no processo de leitura dos textos.

\footnotetext{
5 O foco da metodologia da "sequência didática" (DOLZ et al., 2010) é ensinar ao aluno um determinado gênero textual. Para isso, é organizado sistematicamente um conjunto de atividades escolares que têm como propósito levar o aluno a se apropriar do gênero estudado.

${ }^{6}$ Será usada a sigla PCNs para se referir aos Parâmetros Curriculares Nacionais.
} 


\section{Revista do SELL}

v. $4, n^{\circ} .1$

ISSN: $1983-3873$

\section{1 - A intervenção pedagógica}

No período de fevereiro a maio de 2012, foi desenvolvida com duas turmas de $6^{\circ}$ ano do Ensino Fundamental uma sequência didática de estudo do gênero "conto".

O objetivo era estudar várias versões do conto Cinderela - conto de fadas de origem oral, mas adaptado para a escrita por alguns autores -, sendo que algumas já eram conhecidas pelos alunos. Entretanto, eles não conheciam as versões originais de Charles Perrault e dos Irmãos Grimm, escritas em uma linguagem mais aprimorada e com uma extensão maior em comparação a outras adaptações. A proposta consistia em leitura e discussão dos contos e posterior produção textual.

A escolha da temática e da sequência de contos a serem estudados objetivou apresentar versões criadas em países e épocas diferentes, a fim de levá-los à análise das diferenças e semelhanças entre elas, despertando-os assim para a percepção dos diálogos existentes entre os textos; também pretendia conduzi-los a uma análise aprofundada dos contos lidos no início de sua escolarização para que lançassem um novo olhar para o "já-conhecido"; visava, por fim, a capacitá-los para estabelecerem relações entre os contos e as criações contemporâneas pertencentes a outros domínios, como da televisão, do cinema e da vida cotidiana, ampliando assim seu olhar sobre as produções simbólicas da sociedade.

Diante desses objetivos, foram desenvolvidas as seguintes atividades de leitura:

19a- Leitura de duas cenas da novela televisiva Páginas da vida.

2ª- Leitura do conto Cinderela ou o sapatinho de cristal de Charles Perrault.

3a- Leitura do conto A Gata Borralheira dos Irmãos Grimm.

4-- Leitura do conto Por que o mar tanto chora, versão recolhida por Sílvio Romero 5-.- Leitura do filme Para sempre Cinderela.

Foram realizadas oficinas de leitura, com dia e horário semanais sempre definidos. Ao iniciar o projeto, os alunos foram informados de que fariam atividades de leitura e produção textual. Como resultado, o texto produzido por eles seria redigido em um formato de livro, o qual seria exposto em uma mostra a ser realizada na escola. 


\section{Revista do SELL}

v. $4, n^{\circ} .1$

ISSN: $1983-3873$

Na primeira oficina, foram apresentadas duas cenas da novela Páginas da Vida que dialogavam com os contos que seriam lidos, a fim de estimular nos alunos a capacidade de relacionarem os textos entre si.

Após a exibição do vídeo, com o propósito de que estabelecessem relações entre a narrativa da novela e a de Cinderela, foi-lhes questionado se aquele enredo os remetia a alguma história já conhecida. Eles apontaram semelhanças dessa temática com a de outras novelas, mas não conseguiram recorrer ao conto que parecia evidente.

Feita essa primeira discussão, na qual foram discutidas a construção dos personagens, do enredo, as inúmeras versões que aparecem na TV e no cinema, fez-se a leitura de uma versão de Cinderela ou O sapatinho de cristal de Charles Perrault. Em seguida, os alunos, orientados pela professora, conseguiram estabelecer as relações intertextuais entre a novela e o conto, bem como foram realizadas discussões sobre 0 autor e o contexto histórico, social e cultural do conto, buscando relacioná-lo ao e diferenciá-lo do contexto da novela.

$\mathrm{Na}$ segunda oficina, fez-se uma sondagem com os alunos a respeito da estrutura do gênero conto, a fim de diagnosticar os seus conhecimentos prévios sobre o gênero e de introduzir as noções sobre a estrutura e os suportes onde eles aparecem socialmente.

Para fazer essa análise, foi apresentado o conto $A$ Gata Borralheira dos Irmãos Grimm e realizadas, oralmente e por escrito, atividades de leitura que visavam à contextualização do conto lido, ao reconhecimento da estrutura e da linguagem do gênero "conto", à percepção da intertextualidade presente nos dois contos lidos (Cinderela ou o Sapatinho de Cristal e A Gata Borralheira) e à discussão sobre os suportes e o meio de circulação social dos contos.

Na terceira oficina, foi apresentado aos discentes o conto Por que o mar tanto chora, versão brasileira do conto Cinderela, o qual foi dividido entre os alunos para que fizessem uma leitura dramatizada. Nessa versão, havia boxes com informações sobre o contexto do conto, que auxiliavam na compreensão do texto e no estabelecimento de relações com os contos lidos nas oficinas anteriores.

A classe foi dividida em grupos e cada grupo recebeu quatro questões distintas. Foi-lhes solicitado que as discutissem e depois expusessem as conclusões para a turma. As questões de leitura abordavam os seguintes aspectos: contextualização do conto e sua influência na composição da narrativa; estabelecimento de relações entre o país de origem do conto e as características dos personagens, do espaço, do tempo e dos fatos da narrativa; exploração da intertextualidade presente nos contos lidos nas oficinas 


\section{Revista do SELL \\ v. $4, n^{\circ} .1$ \\ ISSN: $1983-3873$}

anteriores e no conto da oficina atual; interpretação das simbologias presentes no conto, bem como suas semelhanças e diferenças em comparação aos contos lidos anteriormente; atividades comparativas e interpretativas diversas, tanto em relação aos elementos textuais/discursivos e contextuais desse conto quanto em relação a outros já lidos em outras atividades ou momentos particulares de leitura.

Após a resolução e a discussão das questões pelos grupos, realizou-se uma conversa coletiva sobre o texto, na qual foi possível observar a capacidade de compreensão e de interpretação do texto pelos alunos.

Para finalizar o processo de leitura, foi exibido o filme Para sempre Cinderela com vistas a apresentar aos alunos mais uma versão a ser lida. Embora apresentasse semelhanças com os contos lidos no que se refere à construção da narrativa e ao tema abordado, o filme possuía características distintas da perspectiva de gênero discursivo. Diante disso, na atividade proposta, foram discutidas com os alunos as diferenças entre os textos verbais (os contos) e multimodais (o filme), mas o foco foi avaliar a aprendizagem dos alunos quanto à intertextualidade temática, não enfatizando no momento da atividade escrita as questões relativas ao gênero discursivo.

Assim, foi-Ihes proposta uma atividade de leitura e escrita com o objetivo de verificar a compreensão da história e o estabelecimento de relações de intertextualidade entre os textos. A atividade consistia na elaboração de uma resenha do filme. Como os alunos não conheciam o gênero, o objetivo era solicitá-lo como proposta de produção com instruções específicas sobre a composição textual, para, após a produção, transformá-lo em objeto de estudo. As instruções dadas aos alunos requeriam que a produção de texto abordasse as seguintes questões:

- Elaborar um resumo o filme.

- Apontar as semelhanças entre o filme e os contos.

- Apontar as diferenças entre o filme e os contos.

- Fazer uma apreciação do filme.

O trabalho de leitura foi finalizado com essa produção reflexiva escrita dos alunos. 


\section{Revista do SELL \\ v. $4, n^{\circ} .1$ \\ ISSN: 1983-3873}

\section{2 - A coleta dos dados}

A coleta dos dados foi realizada de modos distintos. Como a pesquisadora também era a professora da turma, após cada oficina, anotavam-se em um diário de pesquisa os resultados obtidos durante a intervenção bem como as reflexões sobre o processo. Essas anotações no diário compreendiam duas perspectivas: uma sobre o desenvolvimento dos alunos durante a atividade de sua capacidade de ler os textos e outra sobre o papel do professor nesse contexto.

Também foram recolhidos dois materiais escritos: um questionário sobre a primeira oficina de leitura, no qual eles deveriam expor sua opinião sobre a atividade e apontar, de modo mais geral, as aprendizagens obtidas a partir do trabalho de leitura realizado coletivamente; e uma produção de texto realizada individualmente pelos alunos na última oficina de leitura, com o objetivo de analisar e refletir sobre sua aprendizagem no processo de ensino da leitura no qual estiveram envolvidos.

\section{3 - Análise dos dados}

Na primeira produção escrita, foram obtidos treze (13) questionários respondidos. Eles continham perguntas mais gerais sobre a oficina de leitura e foram respondidos após a atividade. O número inferior ao número de alunos da turma deve-se ao fato de os alunos terem entregado o questionário em outra aula, devido ao término do tempo de aula. Com isso, uma parcela não se comprometeu com a realização da atividade e, por ser um trabalho de pesquisa, a resposta a este questionário deveria ser voluntária.

Duas perguntas do questionário buscavam saber a opinião dos alunos sobre as oficinas e duas pretendiam observar a capacidade de síntese dos alunos sobre as relações de intertextualidade abordadas em sala de aula, a fim de verificar a aprendizagem do que foi abordado e a viabilidade do trabalho proposto. A seguir, são apresentados dois exemplos de questionários respondidos após a primeira oficina de leitura. 


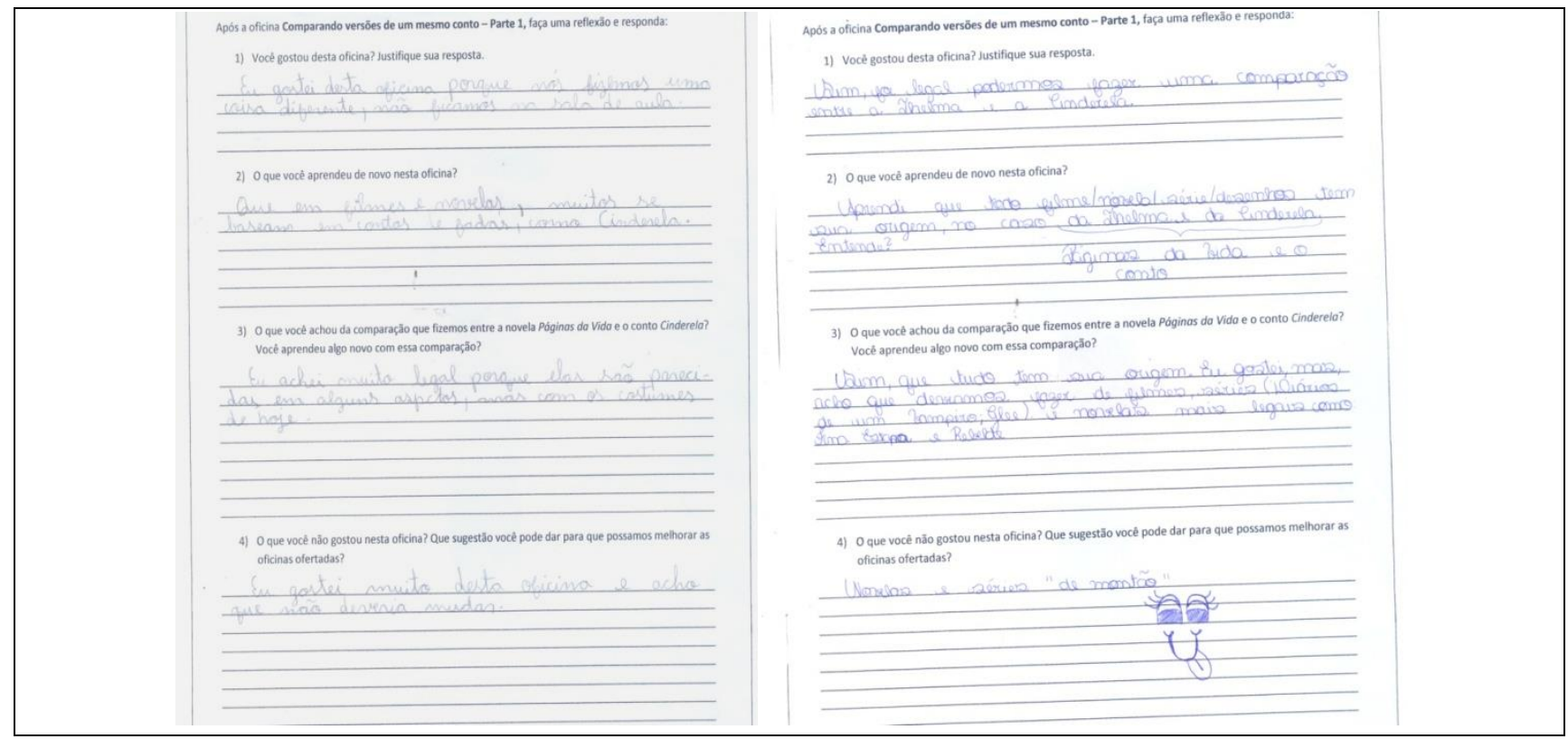

Figura 1: Questionários respondidos na primeira oficina

Nesses questionários analisados, o foco foram as respostas dadas às questões 2 e 3. Dos 13 alunos que o responderam, 55\% perceberam e/ou expuseram sua aprendizagem das relações intertextuais e 45\% não perceberam e/ou não expuseram aprendizagens dessa natureza.

Quanto à natureza das respostas, os alunos abordaram aspectos gerais da intertextualidade, sendo coerentes, de certo modo, com a pergunta, igualmente genérica, que Ihes foi feita. O relevante foi observar que os alunos, cada um a seu modo, conseguiram compreender e estabelecer relações de sentido entre os textos.

Por outro lado, os seis (6) alunos que não identificaram as relações de intertextualidade, ou não conseguiram expor sua aprendizagem, forneceram elementos que indicavam a necessidade de intervenção a fim de propiciar-Ihes uma aprendizagem efetiva.

Outro aspecto de trabalho realizado refere-se ao caderno reflexivo da professorapesquisadora, o qual aponta diferenças entre a leitura oral feita pelos alunos e a leitura escrita apresentada no questionário. Na atividade oral e coletiva, os alunos foram conduzidos pela professora - que os interpelava para que interagissem com o texto, construíssem sentidos e os expressassem. Nessa situação de aprendizagem, eles expressavam reflexões mais detalhadas sobre o texto e conseguiram realizar relações de sentido mais aprofundadas e, muitas vezes, estabeleceram diálogos do texto com a realidade; por outro lado, constatou-se também que as contribuições orais não foram 


\section{Revista do SELL}

v. $4, n^{\circ} .1$

ISSN: $1983-3873$

feitas por todos os alunos, o que indica a tendência comum - mas não desejável - do contexto da sala de aula de apenas um número $X$ de alunos participarem oralmente.

$\mathrm{Na}$ última oficina de leitura, foram elaboradas e cedidas à professor-pesquisadora vinte e seis (26) produções escritas, das quais foram obtidos os seguintes dados:

- 80,7 \% compreenderam e estabeleceram relações intertextuais.

-19,3 \% não compreenderam e/ou não estabeleceram relações intertextuais.

A seguir apresentamos três exemplos de produções dos alunos, realizadas após a última oficina de leitura.

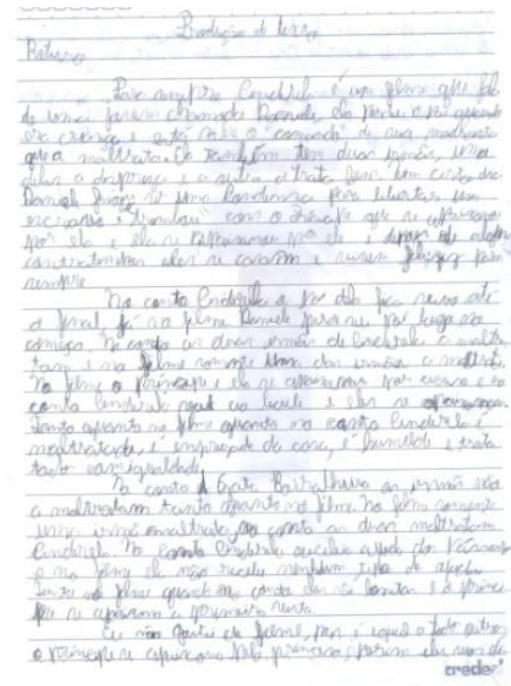

Figura 2: Produção de texto 1

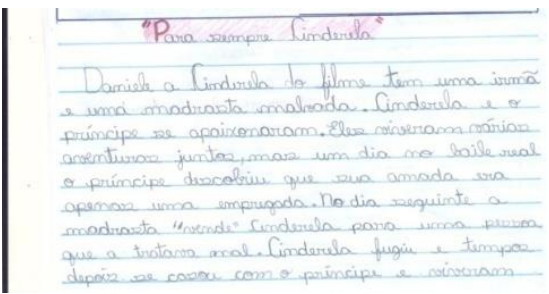




\section{Revista do SELL}

v. $4, n^{\circ} .1$

ISSN: $1983-3873$

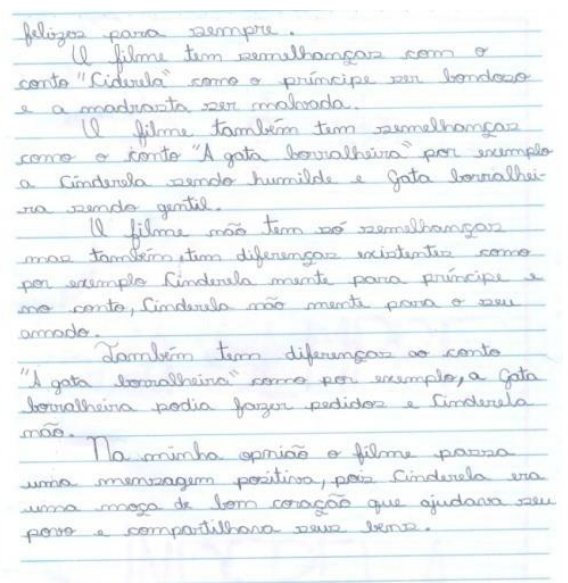

Figura 3: Produção de texto 2

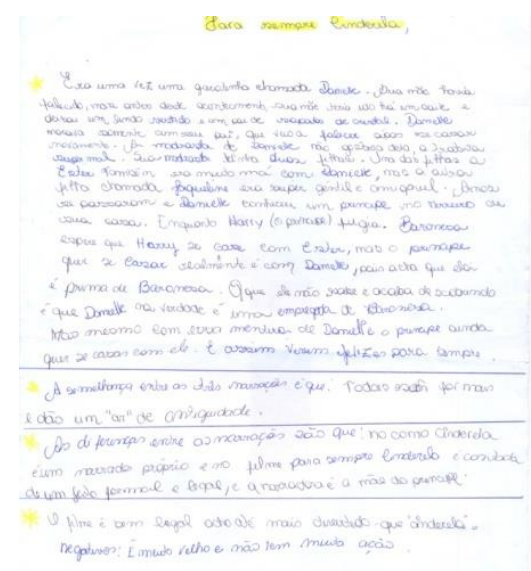

Figura 4: Produção de texto 3

Das produções que atenderam à proposta (80,7 \%), observa-se que as compreensões do texto e as percepções da intertextualidade se deram de modos diversos. Ao estabelecerem as relações de intertextualidade, algumas se detiveram a elementos mais simples e explícitos na narrativa e outras conseguiram abordar elementos mais complexos, realizando análises mais detalhadas e reflexivas em torno dos personagens e do enredo.

Os exemplos a seguir, extraídos dos textos dos alunos, exemplificam casos variados de percepção das relações intertextuais, desde as que revelam maiores índices de aprendizagem até aquelas que não conseguiram estabelecer produtivamente as relações intertextuais existentes e com coerência. Ressalta-se que os resumos não foram 


\section{Revista do SELL}

v. $4, n^{\circ} .1$

ISSN: $1983-3873$

transcritos e manteve-se apenas parte do texto que se relacionava diretamente ao propósito do estudo.

\section{Exemplo 1:}

"No conto Cinderela o pai dela fica vivo até o final, já no filme Daniele perde seu pai logo no começo. No conto as duas irmãs de Cinderela a maltratam e no filme somente uma das irmãs a maltrata. No filme o príncipe e ela se apaixonam por acaso e no conto Cinderela vai ao baile e eles se apaixonam. Tanto quanto no filme quanto no conto Cinderela é maltratada, é empregada da casa, é humilde e trata todos com igualdade.

No conto da Gata Borralheira as irmãs não a maltratam tanto quanto no filme. No filme somente uma irmã maltrata, no conto as duas maltratam Cinderela. No conto Cinderela recebia ajuda dos pássaros e no filme ela não recebeu nenhum tipo de ajuda. Tanto no filme quanto no conto elas são bonitas e o príncipe se apaixona à primeira vista.

Eu não gostei do filme, pois é igual a todos os outros, o príncipe se apaixona pela princesa, porém eles suas diferenças, mas no final o amor vence e eles se casam. O único lado positivo são as lutas muito bem feitas."

\section{Exemplo 2:}

"O filme tem semelhanças com o conto "Ciderela" como o príncipe ser bondoso e a madrasta ser malvada.

O filme também tem semelhanças como o conto "A gata borralheira" por exemplo a Cinderela sendo humilde e Gata borralheira sendo gentil.

O filme não tem só semelhanças mas também tem diferenças existentes como por exemplo Cinderela mente para o príncipe e no conto, Cinderela não mente para o seu amado.

Também tem diferenças ao conto "A gata borralheira" como por exemplo, a Gata borralheira podia fazer pedidos e Cinderela não.

$\mathrm{Na}$ minha opinião o filme passa uma mensagem positiva, pois Cinderela era uma moça de bom coração que ajudava seu povo e compartilhava seus bens.

\section{Exemplo 3:}

As semelhanças entre as três narrações é que: todas são formais e dão um ar de antiguidade.

As diferenças entre as narrações são que: no conto "Cinderela" é um narrador próprio e no filme "Para sempre Cinderela" é contada de um jeito formal e legal, e a narradora é a mãe do príncipe.

O filme é bem legal acho até mais divertido que "Cinderela".

Negativos: é muito velho e não tem muita ação. 


\section{Revista do SELL}

v. $4, n^{\circ} .1$

ISSN: $1983-3873$

O texto 1 explorou, de modo aprofundado, as relações de intertextualidade, enfocando aspectos diversos da narrativa como a identificação de semelhanças e/ou diferenças entre personagens ou objetos presentes nos textos comparados, às ações e às características psicológicas das personagens e ao desenvolvimento do enredo. No referente à apreciação, o aluno manifestou capacidade de dialogar com o filme, atribuindo-Ihe sentidos que expressam sua subjetividade enquanto leitor situado cultural e sócio-historicamente, expressando um ponto de vista crítico sobre o que lê.

O texto 2 explorou, nas relações de intertextualidade, os elementos relacionados às características e às ações das personagens, abordando-os com menor complexidade . Porém, quanto à apreciação, elaborou uma análise interpretativa do texto, em que o leitor demonstrou ser um sujeito capaz de refletir e (re) significar o texto lido, atribuindo-Ihe sentidos conforme a sua leitura.

O texto 3 revelou a dificuldade do aluno em elaborar relações intertextuais, alcançando os objetivos da atividade proposta apenas na primeira frase comparativa do texto, em que ele afirmou: "todas são formais e dão um ar de antiguidade."; e, parcialmente, ao comparar os narradores de cada história, revelando, de certo modo, uma percepção da semelhança e da diferença entre o estilo das narrativas. Por outro lado, não conseguiu desenvolver plenamente a intertextualidade entre as narrativas. Quanto à apreciação, o aluno expressou apenas o seu gosto pessoal, sem, no entanto, fazer reflexões mais complexas que abordariam o tema, o enredo ou os elementos da narrativa.

Desse modo, ao considerar todas as produções analisadas, pôde-se observar que o estabelecimento de relações intertextuais e as apreciações estéticas e/ou críticas sobre o filme revelam modos variados de ler e compreender e, portanto, de pô-los em diálogo entre si e de dialogar com o que se leu.

Percebe-se que os sujeitos da pesquisa identificaram o dialogismo entre textos predominantemente nos seguintes elementos: características de personagens e relações estabelecidas entre eles, elementos relacionados às ações das personagens na narrativa e ao desfecho da narrativa.

Assim, foram pouco mencionados os diálogos entre elementos do enredo, como: os problemas da narrativa, o clímax, a resolução do conflito, as diferenças entre o desenrolar de alguns fatos do filme e dos contos. Com isso, pode-se afirmar que, na maioria das produções, houve uma tendência a analisar os elementos mais básicos e simples da narrativa em detrimento de aspectos mais complexos, que demandam 


\section{Revista do SELL \\ v. $4, n^{\circ} .1$ \\ ISSN: $1983-3873$}

conhecimentos mais aprofundados sobre os elementos da narrativa, bem como maior capacidade reflexiva e analítica.

Em alguns textos, há apreciações interpretativas, nas quais os alunos foram capazes de sintetizar, dialogar com o texto e atribuírem sentidos diversos a fatos ou personagens representados na narrativa, conforme exemplificado nos textos 1 e 2 . No entanto, apenas 38,4\% realizaram apreciações estéticas e dialogaram com o filme.

Os resultados preliminares das análises evidenciam aprendizagens ainda em progresso e que demandam intervenções pedagógicas específicas, a fim de compreender e atender às necessidades de aprendizagem dos alunos.

\section{Reflexão sobre os resultados alcançados}

A partir das análises do corpus e dos resultados alcançados, conclui-se que a intervenção pedagógica foi produtiva no que se refere ao desenvolvimento das novas habilidades de leitura.

Pode-se afirmar que as aprendizagens se deram de modos variados, como são os sujeitos nela envolvidos. Elas expressam um movimento de aprendizagem significativo, no qual se observa uma parcela de resultados concernentes com a intervenção pedagógica, mas também outros que apresentam aprendizagens não consolidadas conforme o esperado, requerendo assim reflexões e propostas de ensino adequadas para que a aprendizagem se efetive.

Essas diferenças resultantes do processo revelam as particularidades que envolvem 0 ato de ensinar a ler para além do código linguístico, pois evidencia que esse deve de ser um processo contínuo na prática pedagógica, a fim de atender aos diversos sujeitos aprendizes.

Observou-se que em uma primeira intervenção pedagógica de leitura é possível alcançar resultados satisfatórios, mas não plenos. Nesse sentido, os diagnósticos feitos após determinado período de intervenção devem conduzir o professor a repensar a prática pedagógica e encontrar caminhos outros para assim atingir os alunos com maiores dificuldades. Isso inclui eleger procedimentos metodológicos diferenciados, temáticas, textos e conteúdos igualmente diversos.

Outro aspecto observado diz respeito ao fato de os dados coletados apontarem diferenças de leitura dos alunos ao serem estimulados oralmente pelo professor em oposição aos momentos em que são solicitados a escreverem suas leituras. Esses dados 


\section{Revista do SELL \\ v. $4, n^{\circ} .1$ \\ ISSN: $1983-3873$}

revelam as particularidades que perpassam o trabalho de leitura em sala de aula e fornecem elementos que permitem compreender o papel do professor nesse contexto.

Diante disso, constatou-se que o professor desempenha papéis distintos no processo de ensino-aprendizagem da leitura: 0 de orientador $e$ de motivador/espectador.

Em sua "função orientadora" (HAIDT, 1999, p.57), ele deve orientar o aluno em sua aprendizagem e auxiliá-lo na construção do próprio conhecimento. No processo de aprendizagem da leitura, isso implica fornecer conhecimentos (linguísticos, enciclopédicos, interacionais, etc.) não dominados pelos discentes, a fim de auxiliá-los a lerem o texto; requer direcionar o raciocínio dos estudantes com intuito de levá-los a perceberem elementos no texto para assim atribuir sentidos. Por fim, essa função também requer que o professor valorize o conhecimento prévio dos alunos e os auxilie no processo de transformação do que já conhecem: antes, de modo fragmentado; depois, de modo organizado, com relações claramente estabelecidas entre o próprio objeto de conhecimento e sua vida cotidiana.

Como motivador ou espectador do processo de aprendizagem, o professor tem a função de apresentar atividades aos alunos que os desafiem a pensar de modo autônomo, a exercitar suas aprendizagens e a mobilizar seus conhecimentos, usando estratégias de leitura já aprendidas e/ou desenvolvidas nos momentos de interação professor-aluno e aluno-aluno.

Da perspectiva do ensino da leitura, seja na função de orientador ou de motivador/espectador, acredita-se que o professor deva ocupar o lugar do leitor maduro (por isso deve de ser um leitor experiente) cuja função é fornecer informações aos alunos e conduzir seu raciocínio, sendo um elo inicial entre o aluno e o texto.

Enfim, deve propor atividades de leitura direcionadas, com o propósito de conduzir o discente a identificar e refletir sobre as questões estéticas, estilísticas, linguísticas, literárias, históricas e socioculturais que concorrem para a constituição dos sentidos dos textos.

\section{Considerações finais}

Os resultados do trabalho evidenciam que houve aprendizagens, mas que há também necessidades que precisam ser incentivadas e (re)trabalhadas no cotidiano 


\section{Revista do SELL}

v. $4, n^{\circ} .1$

ISSN: $1983-3873$

escolar, pois até mesmo os textos que parecem próximos ao universo dos alunos possuem complexidades que demandam um tempo para que eles se apropriem delas e possam analisar os textos com propriedade, estabelecer diálogos entre eles, bem como dialogar com eles.

Constatou-se também que, para o aluno colocar um texto em diálogo com outro e também dialogar com ele, é preciso compreendê-lo plenamente. Não é possível construir sentidos para um texto sem antes se apoderar dele, no sentido de haver uma compreensão plena. Esse foi um aspecto observado na pesquisa e que merece atenção quando se trata de capacitar os alunos a perceberem relações intertextuais.

De modo geral, o trabalho de desenvolvimento das habilidades relativas às "capacidades de apreciação e réplica do leitor em relação ao texto (interpretação, interação)" e, de modo específico, o de identificação da intertextualidade entre contos e textos multimodais pode parecer simples a um leitor maduro, mas é complexo para leitores iniciantes. Eles necessitam desses conhecimentos não só para compreenderem o texto e fazerem uma tarefa escolar, mas, sobretudo, porque precisam se tornar cidadãos letrados, e porque letrados que sejam críticos, saibam dialogar com os textos e se apoderem deles para confrontá-los, concordar com eles ou não, remodelá-los e criarem seus próprios textos, orais ou escritos.

\section{Referências}

ANTUNES, Irandé. Análise de textos: fundamentos e práticas. São Paulo: Parábola Editorial, 2010.

BRASIL. Ministério de Educação. Secretaria de Educação Fundamental. Parâmetros Curriculares Nacionais. 1ํ e 2ํo ciclos: Língua Portuguesa. Brasília: MEC/SEF, 1997.

BAKHTIN, M. Os gêneros do discurso. In: BAKHTIN, M. Estética da criação verbal. 3. ed. São Paulo: Martins Fontes, 2000. p. 277-287.

DOLZ, Joaquim; NOVERRAZ, Michèle; SCHNEUWLY, Bernard. Sequências didáticas para o oral e a escrita: apresentação de um procedimento. In: SCHNEUWLY, Bernard; DOLZ, Joaquim. Gêneros orais e escritos na escola. Tradução e organização: Roxane Rojo e Glaís Sales Cordeiro. 2. ed. Campinas, SP: Mercado de Letras, 2004.p. 81-108.

DOLZ, Joaquim; SCHNEUWLY, Bernard. Gêneros e progressão em expressão oral e escrita - elementos para reflexões sobre uma experiência suíça (francófona). In: SCHNEUWLY, Bernard; DOLZ, Joaquim. Gêneros orais e escritos na escola. 2. ed. 


\section{Revista do SELL}

v. $4, n^{\circ} .1$

ISSN: $1983-3873$

Tradução e organização: Roxane Rojo e Glaís Sales Cordeiro. Campinas, SP: Mercado de Letras, 2004. p. 35-60.

ESTÉS, Clarissa Pínkola (Org.). Contos dos Irmãos Grimm. Tradução de Lia Wyler. 1.ed. Rio de Janeiro: Rocco, 2005.

HAIDT, Regina Célia Cazaux. Curso de didática geral. 7. ed. São Paulo: Ática, 1999.

KLEIMAN, Ângela B. Letramento e suas implicações para o ensino de Língua materna. Acesso em 08 dez. 2010. Disponível em: <http://www.letramento.iel. unicamp. br/portal $/ ? \mathrm{p}=213>$.

KLEIMAN, Ângela B. Preciso "ensinar" letramento? Não basta ensinar a ler e a escrever?. Campinas: Cefiel/Unicamp; MEC, 2005. Acesso em 08 dez. 2010. Disponível em: $<$ http://www.iel.unicamp.br/cefiel/alfaletras/biblioteca_professor/arquivos/5710.pdf >.

KOCH, Ingedore G. Villaça; BENTES, Anna Christina; CAVALCANTE, Mônica Magalhães. Intertextualidade: diálogos possíveis. 2. ed. São Paulo: Cortez, 2008.166 p.

$\mathrm{KOCH}$, Ingedore Villaça; ELIAS, Vanda Maria. Ler e compreender: os sentidos dos textos. 2. ed. São Paulo: Contexto, 2007.

$\mathrm{KOCH}$, Ingedore Villaça; ELIAS, Vanda Maria. Ler e escrever: estratégias de produção textual. 2. ed. São Paulo: Contexto, 2011.

MATENCIO, Maria de Lourdes Meirelles. Leitura, produção de textos e a escola: reflexões sobre o processo de letramento. 1. ed. Campinas, SP: Mercado de Letras, Editora Autores Associados, 1994.

PERRAULT, Charles. Contos de Perrault. Tradução de Regina Regis Junqueira. 4. ed. Rio de Janeiro: Editora Villa Rica, 1994.

PHILIP, Neil. Volta ao mundo em 52 histórias. Ilustração de Nilesh Mistry. Tradução de Hildegard Feist. 2. ed. São Paulo: Companhia das Letrinhas, 1998.

PISA: Programme for International Student Assessment - Programa Internacional de Avaliação de Alunos. Campos dos Goytacazes, RJ: Instituto Federal de Educação, Ciência e Tecnologia Fluminense. Disponível em: <http://www.iff.edu.br/cooperacaointernacional/PISA programa\%20Internacional\%20de\%20avaliacao.pdf>. Acesso em 23 abril de 2013.

ROJO, ROXANE. Letramento e capacidade de leitura para a cidadania. Disponível em: $<$ http://web.me.com/rrojo/Roxane Rojo/ Blog/Entr\%C3\%A9es/2009/2/24_Letramento Espa\%C3\%A7o de leitura_para_a cidadania files/Rojo_2004_CapacidLeitura_1.pdf >. Acesso em 26 out. 2010.

SANT'ANNA, Affonso Romano de. Paródia, paráfrase e Cia. 6 ed. São Paulo: Ática, 1998. $96 \mathrm{p}$. 


\section{Revista do SELL}

v. $4, n^{\circ} .1$

ISSN: $1983-3873$

SOARES, Magda. Letramento: um tema em três gêneros. 4. ed. Belo Horizonte: Autêntica Editora, 2010.

TV GLOBO. Páginas da Vida. Thelma chega a mansão dos Andrade. (Capítulo 061). Disponível em: <www.youtube.com/watch?v=mObAxCvH6c8>. Acesso em 10 fev. 2012.

TV GLOBO. Páginas da Vida. Thelma e Jorge se casam em linda cerimônia. (Capítulo 203). Disponível em: <www.youtube.com/watch?v=QprOYgYgbuM.> Acesso em 10 fev. 2012. 